

\title{
Challenging Human Enhancement
}

\author{
Alberto Giubilini \\ Sagar Sanyal \\ DOI:10.1093/acprof:0so/9780198754855.003.0001
}

\begin{abstract}
Keywords
The chapter presents an overview of the major lines of debate in the ethics of human enhancement. While permissive and restrictive positions on enhancement can be contrasted, the conservative camp (which is the focus of the book as a whole) is a specific subset of the latter. Although the restrictive but non-conservative position is outlined, most of the chapter is devoted to the themes and arguments of the conservative camp. To give a well-rounded account of the conservative position, the chapter begins with connections to the tradition of social conservatism, before moving to prominent themes in the conservative opposition to human enhancement. These include the charge of 'playing God', the appeal to intuition or emotion, human dignity, and the connection to eugenics. The final section of the chapter surveys some of the recent work in moral psychology that the human enhancement debate increasingly draws upon.
\end{abstract}

Keywords: human enhancement, conservatism, dignity, playing God, eugenics

(p.1) 1.1 Human Enhancement: Mapping the Terrain In bioethics the term 'human enhancement' refers to any kind of genetic, biomedical, or pharmaceutical intervention aimed at improving human dispositions, capacities, and well-being, even when there is no pathology to be treated (Giubilini and Sanyal 2015; Juengst and Moseley 2015). Selecting embryos before implantation during in vitro fertilization (IVF) procedures, inserting or deleting gene sequences, taking enhancing drugs for better physical or mental performance, pursuing life extension through stem cell applications and regenerative medicine are all examples of interventions that are, or might 
soon be, technically possible. The completion of the Human Genome Project at the beginning of the new millennium has provided a great deal of knowledge about human DNA and about the correlation between certain gene sequences and certain phenotypic traits. This knowledge holds promise for making genetic human enhancement not only feasible but also tailored to people's specific needs and desires.

There are two main ways of conceptualizing human enhancement with regard to the aims and scope of medicine. In general, those who oppose human enhancement think that, by going beyond what is currently seen as normal health, enhancement is beyond the proper ends of medicine (President's Council on Bioethics 2003; Pellegrino 2004; Sandel 2004). Those in favour typically endorse a welfarist approach to medicine, according to which therapy and enhancement share the same aim of increasing 'the chances of leading a good life in the relevant set of circumstances' (Savulescu, Sandberg, and Kahane 2011 , p. 7), which is the aim of medicine broadly understood (Savulescu 2007; Harris 2009; Kamm 2009; Savulescu, Sandberg, and Kahane 2011). The difference between these two main conceptions of enhancement is rooted in different stances on the moral relevance of the distinction between therapy and enhancement. The non-medicine approach takes the distinction to be factually and morally important, while the welfarist approach sees the 'normality' that medicine aims to restore as a merely statistical notion, subject to change over time, with no moral significance (Bostrom and Roache 2008).

(p.2) Positions regarding the morality of enhancement can be divided into three main categories (Giubilini and Sanyal 2015):

1. Some authors believe that people should be free to enhance themselves (and, according to some, also their offspring) through various means (including - should it become possible-engineering embryos). While these scholars do not endorse indiscriminate enhancement, they tend to highlight the positive aspects of enhancement and propose measures to counteract possible negative externalities. For example, some suggest that enhancements should not be imposed by the state, or that they should be subsidized for certain groups of people. Authors in this category are sometimes referred to as 'bioliberals'.

2. Some people take a more moderate approach. While they do not have any objection to enhancement in principle, they place more emphasis on the distinction between objectionable and non-objectionable forms of enhancement. Various considerations inform their cautious approach, including distributive concerns about the wealthy having access to enhancements that are not accessible to the poor, and concerns about the safety of specific techniques of enhancement.

3. Finally, some scholars have in-principle objections to human enhancement. An in-principle objection can be based either on the idea 
that enhancements in certain spheres of activity violate the rules that define the activity in question (e.g. doping in sport) or on the idea that human nature has a special status which enhancement would violate, particularly when carried out in radical forms, such as genetic design of offspring. Some of the language invoked at this more restrictive end bears recognizable relation to the tradition of conservative social thought, particularly terms such as 'sanctity', 'playing God', and 'human dignity'.

Some opponents of human enhancement have explicitly cast themselves as conservative. They have drawn connections to the broader conservative tradition. Therefore, in spite of some problematic implications of applying political categories to the bioethical debate, ${ }^{1}$ we reserve the adjective 'conservative' for the third type of position, and we characterize nonconservative arguments for restrictions on enhancement (which support the second position in the taxonomy provided above) as 'restrictive'. We speak (p.3) of 'proponents of enhancement' or 'permissive positions regarding enhancement' instead of 'bioliberals' to avoid the impression that these positions are either entailed by the tradition of political liberal thought or are only available to those with liberal commitments.

While conservative opposition to human enhancement can be seen as a monolithic position based on a well-defined set of ethical stances (which will be reviewed in the sections below), restrictive and permissive positions are characterized by internal differences and significant internal disagreements. Such disagreements depend on different factors. For example, they might depend on the type of enhancement in question: some people who are generally in favour of enhancement oppose specific types of enhancement, such as moral enhancement (e.g. Harris 2011). Or internal differences might concern the degree of the enhancement in question: some people who are generally in favour of enhancement distinguish between more radical and impermissible forms of enhancement that might lead to a new species (post-humans) and more moderate and acceptable forms of enhancement which remain within the range of normality for our species (e.g. Agar 2013). Or, again, some might say that certain methods of enhancement are more problematic than others-for example, that genetic manipulation of embryos is more problematic than selecting a certain embryo in IVF procedures, since only in the first case would the intervention change the genetic identity of an identifiable individual.

In this introductory chapter we will focus mainly on conservative positions and, to a lesser extent, on restrictive positions. We will discuss permissive positions only to illustrate how they might respond to some typical conservative or restrictive objections. Section 1.2 provides a very brief historical overview of the conservative tradition and places the bioethics and human enhancement debates in this context. Sections 1.3-1.6 cover some recurring themes in moral 
conservative opposition to human enhancement. Section 1.3 looks at claims from some conservatives that bioethics debates generally, and the human enhancement debate specifically, have been restricted by assumptions that have been variously characterized as 'liberal', 'analytic', or 'instrumentalist'. It is alleged that the perspectives on enhancement recently raised by conservative writers had been excluded by the debate. Section 1.4 looks at the charge that enhancement, especially genetic enhancement, amounts to playing God. Section 1.5 looks at the moral relevance of intuition and emotion, focusing in particular on the idea of the 'wisdom of repugnance', which some conservatives have used to oppose certain uses of biotechnologies. Section 1.6 looks at appeals to human nature and to dignity. In Section 1.7 we turn to some reasons to restrict or oppose human enhancement that are not peculiar to the conservative tradition. This serves both as a way to round off the survey of opposition to enhancement, and as a contrast that helps us see what is truly distinctive about the opposition from the moral conservative camp.

(p.4) 1.2 Conservatism: from the French Revolution to the Biotechnology Revolution

Conservatism is, loosely, a philosophy of reaction to developments that threaten tradition (see e.g. Hirschman 1991; Scruton 2001). It stemmed from the aristocratic opposition to the egalitarian ideas of the French Revolution. According to the eminent historian of conservatism Russell Kirk,

the essence of social conservatism is preservation of the ancient moral traditions of humanity. Conservatives respect the wisdom of their ancestors [...]; they are dubious of wholesale alteration. They think society is a spiritual reality, possessing an eternal life but a delicate constitution; it cannot be scrapped and recast as if it were a machine. (Kirk 1994, p. 8)

Today, these kinds of concern are often raised with respect to one of the key priorities of conservatism: bioethics (Levin 2003, p. 53). Addressing the challenges posed by bioethics has required conservatives to focus more specifically on moral issues rather than on social or political issues. The meaning and value of life and death, the notion of personhood, the extent to which human life can be used as a commodity or a means for someone's ends-all are core concerns of what can be labeled moral conservatism in bioethics.

More recently, scientific advances, particularly in the field of biotechnologies, have provoked a new set of ethical discussions among moral conservatives in relation to human enhancement.

With the possibility of using biotechnologies to alter natural human capacities comes a set of concerns not previously expressed in bioethical debates. As Charles Krauthammer put it, rather than concerns about using and destroying early forms of human life, '[w]hat really ought to give us pause about research [...] is what monsters we will soon be capable of creating' (Krauthammer 2002, 
p. 202). With human enhancement, the issues at stake concern the moral status of human nature, the meaning of human dignity, the permissibility of playing God, and modifying what some people see as a gift (from God or from nature) (Kass 1997; Fukuyama 2002; Levin 2003; Sandel 2004, 2007; Cohen 2006). Also, moral conservatives have questioned the permissibility or wisdom of discussing potential applications of biotechnology. Some fear that such a discussion might break certain taboos that it might be better to leave untouched (Levin 2003).

Contemporary conservatives in bioethics share a 'moral anthropology' that Eric Cohen (2006) has condensed into the following points: the recognition of a special dignity in all human beings, which is an essential feature of human nature rather than something based on contingent properties (e.g. rationality or self-awareness); a recognition of the special meaning of our mortality as the sign of the mystery surrounding human experience-that is, 'something beyond the living person's comprehension, something we cannot finally master' (Cohen 2006, p. 49); a set of principles and values about the nature of the family, involving precise prescriptions about the modalities of (p.5) procreation which describe as immoral 'various technological possibilities-like human cloning, gamete engineering, and the creation of man-animal hybrids-that would exert novel parental control over the genetic makeup of new life' (Cohen 2006, p. 50); the importance of human flourishing based on authentic human experience and efforts (as opposed to artificially enhanced minds and bodies); and an agenda for public policy that proposes, among other things, bans on creating human embryos for research purposes, non-traditional and 'unnatural' ways of creating babies, the creation of human-animal chimera embryos, and buying and selling human body parts.

Whereas Cohen lists substantial aspects, there are formal aspects that are at least as distinctive of the moral conservative movement. Ruth Macklin (2006), a critic of the conservative movement in bioethics, lists the following features as characteristic of what she calls 'the new conservative movement in bioethics' (Macklin 2006, p. 34): a propensity to use poetic and metaphoric language; repeated appeals to emotion, sentiment, and intuition; what she calls a 'mean spirited rhetoric'; and a tendency to see a proliferation of projects-that is, of concerted efforts by organized groups which conservatives oppose (e.g. the 'eugenic project', the 'biotechnology project', and so on).

\subsection{Instrumentalist versus Substantive Bioethics}

Some conservatives have characterized the existing bioethics debates generally, as well as the human enhancement debate specifically, as either liberal or analytic in a sense that contrasts with their own approach to the same issues. Michael Sandel suggests that liberals reach first for the language of rights, autonomy, and fairness, but that some of the hardest questions facing bioethics 
and the enhancement debate are not readily elucidated in these terms (Sandel 2007, pp. 9-10). Leon Kass finds the analytic approach to bioethics wanting:

With its capture by analytic philosophy, [...] [bioethics] has by and large come to content itself with analyzing moral arguments, reacting to new technological developments and taking on emerging issues of public policy, all performed with a naïve faith that the evils we fear can all be avoided by compassion, regulation and a respect for autonomy. [...] its practitioners, with few exceptions, have turned the big human questions into pretty thin gruel. (Kass 1997, p. 18)

In a sympathetic history of the American President's Council on Bioethics under Leon Kass, Adam Briggle argues that the council's lasting value was to broaden the sorts of question considered in bioethics beyond certain instrumental ones (Briggle 2010). The alternative to this instrumentalist approach is described as a 'rich' or 'substantive' bioethics that extends discussion to identifying and assessing the implicit ends of certain uses of technology.

Consider a parent's decision whether to genetically enhance an embryo. The parent may implicitly assume the end of giving the child the best shot at being smart, tall, or sociable. The liberal approach, it is charged, would focus on the parent's liberty to choose whether to enhance, and on the potential harm to the future child. A more (p.6) substantive approach, the argument runs, would reconsider the wisdom of allowing all parents to aim for the end of greater intelligence, height, or sociability. If there is pervasive use of genetic enhancement of embryos, then over time the distribution of abilities among the population changes too. In due course, it may become irresponsible for parents not to enhance their offspring, as the failure to do so would place their children at a disadvantage compared with the new norm for intelligence, height, or sociability (Briggle 2010, p. 66).

\subsection{Playing God}

Proponents of human enhancement are often accused of playing God with human nature. The charge is not necessarily based on religious worldviews. There is a metaphorical sense of the expression 'playing God' which makes the objection available to non-theists as well. Such metaphorical use of the playing God objection is based on the idea that some interventions would violate some intrinsic sanctity of nature, which does not derive from God (for a discussion, see Peters 2002).

In general, the accusation refers to an incautious attitude displayed by human enhancement advocates. Enhancing human nature while disregarding the potential and/or unknown risks reveals a certain hubris. Humans are not omniscient and benevolent, and might therefore overlook the risks of tampering with genes. 
Michael Sandel famously advanced a secular version of the playing God objection to human enhancement through genetic engineering (Sandel 2007). For him, one limitation of humans' drive to mastery is a failure to appreciate what he calls the giftedness of human life, or, with a more emphatic phrase, its 'openness to the unbidden'. Sandel thinks that this failure would jeopardize humility and solidarity among humans because mere chance (to which we all are equally subject, according to him) would be replaced by humans' choices and hyper-agency in determining exactly what kinds of people will exist. This hyperagency would generate an 'explosion' of responsibility that might be destabilizing for our ethics-making the individual responsible for many more features of their situation (or their offspring's situation) than they are at present.

The playing God objection can also take the form of a warning that genetic manipulation technologies would blur existing species boundaries-that we would be able to create new species (Annas, Andrews, and Isasi 2002). There are some difficulties involved in sharpening this worry. Eric Juengst notes that we cannot literally preserve the species against all genetic change because genetic profiles associated with a species do change, as existing individuals pass away and new ones are born. Quite without any exogenous intervention in the process, the typical genome of a given species is likely to vary both over time and across populations that are geographically separated with little interaction. If we want to hold one species-typical genome as sacrosanct, then there is an arbitrary decision to take a snapshot at a particular point in time and space to yield the definition of species-typical (Juengst 2009, p. 50). This arbitrariness seems to make the sense of sacrosanct inviolability less plausible.

(p.7) For some, the worry is not about species integrity per se but about what the biological features of a species mean for its moral status (Annas, Andrews, and Isasi 2002). For instance, it might be thought that human rights attach to individual humans because of their possessing some species-typical characteristics. A subspecies of humans created by genetic intervention (or even by enhancement more generally) might come to possess the relevant characteristics to such a heightened degree that it no longer makes sense to assign ordinary humans as much moral status as the new subspecies. For a critique of this worry, see Douglas (2013).

\subsection{The Wisdom of Intuitions and Emotions}

\subsubsection{Intuition, Emotion, and Mystery}

Some conservatives place great weight on intuitions and emotions such as disgust, repugnance, and revulsion. They claim that through disgust, a functioning moral agent recognizes moral violations when seeing the unthinkable happen (Kekes 1998, p. 106). Leon Kass famously defended intuitions and emotions as offering reliable moral guidance in the field of biotechnologies. He suggested that there is wisdom in our feelings of repugnance towards certain biotechnologies, such as human cloning and IVF 
(Kass 1997). Our inability to express what exactly is wrong with incest or cannibalism does not mean that these practices are acceptable, he urges. Similarly, the inability to fully articulate our opposition to biotechnologies does not constitute sufficient reason to endorse things such as human enhancement, medically assisted reproduction, or human cloning. Kass acknowledges that 'revulsion is not an argument' and grants that 'some of yesterday's repugnancies are today calmly accepted'. Nonetheless, he adds that in crucial cases 'repugnance is the emotional expression of deep wisdom, beyond reason's power to fully articulate it' (Kass 1997, p. 20). 'To pollutions and perversion,' he continues, 'the fitting response can only be horror and revulsion; and conversely, generalized horror and revulsion are prima facie evidence of foulness and violation' (Kass 1997, p. 21).

Another example of reliance on intuitions and emotions, rather than rational arguments, ${ }^{2}$ is the conservative approach to the idea of human dignity. The role of dignity in the enhancement debate will be discussed more extensively in the Section 1.6. Worth noting here is that moral conservatives are often very explicit in admitting that the full appreciation of human dignity is something we grasp through intuition rather than something for which we advance reasons and arguments. The fact that many of them devote tens and tens of pages (President's Council on Bioethics 2008, particularly Kass' contribution at pp. 297-331) to discussing something that they think cannot be rationally demonstrated can be seen as either surprising or, conversely, consistent with (p. 8) their assumption that no simple, straightforward definition of dignity can be provided. Thus, for instance, Eric Cohen candidly admits that, 'of course, we can never prove rationally that all human beings possess equal dignity or that human beings possess any dignity at all' (Cohen 2006, p. 48). Meilaender finds the only secular grounds for the idea of dignity in the 'mystery of human condition' (Meilaender 2008, p. 265); the same idea of mystery seems to lurk behind Francis Fukuyama's claim that what grants humans their special dignity is some not-better-clarified factor X-that is, 'some essential human quality underneath' which is what remains 'when we strip all of a person's contingent and accidental characteristics away' (Fukuyama 2002, p. 149). In his discussion of human dignity, Leon Kass claims that, despite the difficulties in clearly articulating reasons in support of the idea of dignity, 'we can in fact recognize dignity, both when we see it shining and when we see it extinguished' (Kass 2008, p. 306).

Emotions and intuitions also ground moral sanctions of what is perceived as polluting holiness and corrupting the venerable, in the form either of God or of the natural order. Such sanctions are often connoted as taboos (Levin 2003). Many conservatives take taboos to be important for the functioning and stability of societies because of the 'inarticulate awe' they inspire in many people (Levin 2003, p. 64). Because taboos are often grounded in strong intuitions or emotions, there is a tension between the desire to preserve them and the desire 
to engage in public debates on a taboo topic. Preserving a taboo implies refraining from rational analysis of it, even when the analysis aims to defend the core of the taboo. Yet many conservatives want to engage in public debate, which requires arguments and publicly accessible evidence and reasons. Yuval Levin has called this 'the paradox of conservative bioethics':

Bioethics is necessarily focused on the deepest and most sensitive of human moral intuitions and taboos [...]. At the same time, it is also directed toward policy, which in a liberal democracy rightly means that it must be an ethics of fully public arguments. It is therefore in the business of public arguments about taboos. [...]. Herein lies the paradox of conservative bioethics. (Levin 2003, p. 54)

Admittedly, grounding their views in intuitions and feelings of revulsion poses some problems to moral conservatives when they want to defend their positions in the public square if interlocutors do not share the intuitions and feelings-as is likely to be the case with regard to repugnance at human cloning. Indeed, it makes the conservative position less likely to succeed in influencing policymaking in liberal Western societies, where public policies are mainly based on the no-harm principle (Roache and Clarke 2009, p. 7).

Levin suggests that because the public square requires participants in public debate to provide arguments in support of a certain position, conservatives should try to provide more and better arguments. However, a closer look at his proposal seems to suggest that this seeming openness to arguments and reasons is a limited one. He claims that a conservative argument defending the truth in taboos 'should begin from a sense of what is humanly important' (Levin 2003, p. 64 ), which, without elaboration of how to arrive at this sense seems to bring us back to the intuitive and emotional sphere.

(p.9) Aside from the difficulties related to bringing the conservative view into the public sphere, the reliance on intuitions and gut feelings defended by conservatives is problematic for at least three other reasons. First, intuitions often change over time. Initial strong opposition to IVF has mostly faded away, for instance. So an independent criterion would be required to determine when intuitions are trustworthy and when they are not. Second, society and technology have changed significantly since the time of our ancestors: our set of intuitions might have evolved to meet the demands of a past environment, and may be unsuited to today's society (Singer 2005, pp. 347-8). Third, intuitions are subject to cognitive biases that render them unreliable. This is especially true when technologies put intuitions to work under completely novel circumstances, as in the case of human enhancement (Roache and Clarke 2009). Indeed, one of the most common accusations raised against conservative positions in the enhancement debate is that of being subject to cognitive biases, such as a 
'status quo' bias, and that these biases are due to unanalysed intuitions and emotions (Bostrom and Ord 2006; Kahane and Savulescu 2013; Giubilini 2015).

\subsubsection{Appeals to Literature}

Appeals to literary scenarios or expressions are a common argumentative device among moral conservatives. An approach that is based on intuitions, emotions, and the notion of 'mystery' is more likely to find resources in poetic and rhetorical language than in argumentation and cool reasoning. Thus Fukuyama's criticism of the biotechnology revolution starts off with the mention of Huxley's Brave New World and Orwell's 1984 in the first five lines of the first chapter. It is not so obvious, Fukuyama says, what is wrong in Huxley's Brave New World in which no one is hurt and everybody has their desires immediately satisfied. Still, we believe that such a world is undesirable even if we struggle to formulate the reasons for this view (Fukuyama 2002, pp. 5-6). The implicit suggestion is that prospects opened by biotechnologies are making our world so similar to the 'brave new' one that the fact that we cannot fully articulate the reasons against it does not mean we should not oppose it.

In a similar fashion, Kass writes that 'the people dehumanized à la Brave New World are not miserable, don't know that they are dehumanized, and, what is worse, would not care if they knew. They are, indeed, happy slaves with a slavish happiness' (Kass 1985, p. 35, quoted in Fukuyama 2002, p. 6).

Similarly, in discussing the risk that human life might become the product of other people's choice and thus lose its gifted character, Michael Sandel describes the scenario of the movie Gattaca, 'in which parents routinely screen embryos for sex, height, immunity to disease and even IQ'. 'There is something troubling', he writes, 'about the Gattaca scenario, but it is not easy to identify what exactly is wrong with screening embryos to choose the sex of our children' (Sandel 2004, p. 53). It is easier to point out that we do not want to live in a world like that.

It is interesting to note here that Sandel's point against the 'drive to mastery' is supported not by a direct argument but by an attempt to explain why people perceive (p.10) Gattaca-like scenarios as wrong. In the case of performanceenhancing biotechnologies, for instance, he writes that

as the role of enhancements increases, our admiration for the achievement fades-or, rather, our admiration shifts from the player to his pharmacist. This suggests that our moral response to enhancement is a response to the diminished agency of the person whose achievement is enhanced.

He therefore concludes that the idea of the giftedness of life is the only way 'to account for what we admire about human activity', and presumably what we do not admire about human enhancement (Sandel 2004, p. 54). 
These examples suggest that the function of literary examples for conservative authors differs from the typical function of thought experiments in philosophical arguments. While both aim to prompt certain emotional and intuitive reactions in the audience through fictional cases, traditional thought experiments typically rely on analogies between improbable scenarios and more realistic ones to test certain theories (e.g. the doctrine of double effect or the moral difference between doing and allowing in trolley problem scenarios). Literary examples in the enhancement debate, on the other hand, are not presented as unrealistic test scenarios but as likely consequences of the application of the principles informing the pro-enhancement positions.

\subsection{Human Dignity and Human Nature in the Enhancement Debate} Human dignity is frequently invoked by conservatives to argue against human enhancement. A representative overview of the conservative appeal to dignity is provided by the collection of essays Human Dignity and Bioethics, commissioned in 2008 by the President's Council on Bioethics. It gathers contributions by prominent contemporary conservative thinkers (as well as a few nonconservatives).

Providing a single definition of human dignity would be impossible because, as many conservatives themselves recognize, 'the term itself is abstract and highly ambiguous' (Kass 2008, p. 306; for a similar assessment, see also Fukuyama 2002 , p. 148). As a result, they propose different and sometimes conflicting interpretations. Since a working definition is needed, however, we present here the general definition proposed by Patrick Lee and Robert George because it is sufficiently broad to be considered as acceptable by almost anyone:

The dignity of a person is that whereby a person excels other beings, especially other animals, and merits respect and consideration from other persons. (Lee and George 2008, p. 410)

Different interpretations of human dignity depend not only on different possible definitions of 'person', 'excellence', and 'respect' but also on the different understandings of human nature and of the foundations of dignity.

\section{(p.11) 1.6.1 Dignity of Human Nature}

The discussion of human dignity in conservative circles assumes there is something special about human nature that confers on any human a moral status that is a) superior to that of any other living being and b) the same for all human beings (regardless of age, level of development, capacities). In the following passage, for instance, Lee and George explain 'the nature and basis of human dignity' by a direct appeal to human nature:

The criterion for moral worth must be the possession of a property that does not itself vary in degree-it must, that is, be the possession of a nature. Being of moral worth must be grounded in an entity's existence as 
a substance of a certain sort [...] rather than in the possession of a set of accidental or variable properties. (Lee and George 2008, p. 415)

In similar vein, Eric Cohen writes:

All members of the human family-all living human bodies-have a human life, and therefore deserve the respect that such membership commands. (Cohen 2006, p. 47, emphasis added)

And here is Francis Fukuyama:

The most significant threat posed by contemporary biotechnology is the possibility that it will alter human nature and thereby move us into a 'posthuman' stage of history. This is important [...] because human nature exists, is a meaningful concept, and has provided a stable continuity to our experience as a species. It is, conjointly with religion, what defines our most basic values. (Fukuyama 2002, p. 7)

Liberals may object to this normative conception of human nature on various grounds. They might point out that alterations to human nature have always characterized our species (Lewens 2012); or that human nature cannot have normative value unproblematically because it contains both good and bad aspects; or that our conception of the good is independent of, and indeed is used to evaluate, human nature (Buchanan 2008).

There are, however, other ways in which human nature can be deployed to support the idea of human dignity. Appeals to human nature often ground concerns about the threat posed by enhancement to the idea of a natural equality among human beings. By sharing the same human nature, humans, qua humans, have equal dignity. Such appeals can be drawn out in either a religious or a secular vision.

As Meilaender notes, 'we are equal to each other, whatever our distinctions in excellence of various sorts, precisely because none of us is the "maker" of another one of us. We have all received our life-equally-as a gift from the Creator' (Meilaender 2008, p. 264). All that is valuable and dignified in humans is given them by God through the nature He creates, hence the normative status of human nature. If we strip away the idea of its religious aspect, the result resembles Sandel's secular 'ethics of giftedness' based on the 'appreciation of the gifted character of human powers and achievements' (Sandel 2004, p. 55). Technologies such as preimplantation embryo selection threaten to make some humans the authors of the talents and powers of others. The President's (p.12) Council on Bioethics report entitled Human Cloning and Human Dignity makes the point by contrasting begetting with making, suggesting that a child made 
according to parents' wishes would not have the same dignity as a begotten child (President's Council on Bioethics 2002, p. 112).

\subsubsection{Foundations of Human Dignity}

An important distinction within conceptions of human dignity is that between the comparative, or aristocratic, notion and the non-comparative, or egalitarian, notion (Lee and George 2008; Meilaender 2008). The former is the notion of the full 'dignity of being human', a notion conveying a sense of worthiness and nobility that is found not in every human being but only in those with certain excellences, virtues or capacities. The non-comparative egalitarian notion is the basic 'dignity of being human', which is shared by any form of human life but which cannot, according to Kass, be shown to have any ontological or theoretical grounds (Kass 2008, pp. 316-20).

Kass finds shortcomings in both conceptions when considered separately. The first is too exclusive and the second lacks a satisfactory justification. He therefore proposes a third notion of dignity, which he calls the 'dignity of being in-between' (Kass 2008, p. 324). The view casts humans as halfway between the other animals and God. Humans are god-like and have aspirations towards what is higher, and therefore a human is 'more than an animal' (Kass 2008, p. 323). However, humans are dependent on their embodied nature for everything high about human life. On Kass' approach, the aristocratic and egalitarian conceptions are reconciled through their mutual dependence. Human flourishing and excellence depend on the merely animal aspects of life which all forms of human life share. These animal aspects are, in turn, dignified by being integrated with the higher functions that are typical of human nature (Kass 2008, pp. 321-2). Although conceptually sophisticated, when it comes to practical guidance about altering human nature, this third conception seems to boil down to an endorsement of the non-comparative notion of dignity. As Kass writes in discussing the implications of the in-between notion of dignity, 'any man's very being requires that we respect his life' (Kass 2008, p. 323).

Eric Cohen argues that even though most conservatives on this issue come from a religious tradition, the idea of dignity informing their conservatism does not have a religious foundation (Cohen 2006). Nonetheless, it is difficult to see how a religious foundation can be turned into a secular one in some discussions of dignity.

\section{Consider Meilaender, for instance:}

It may be that we cannot make good sense of an egalitarian and noncomparative understanding of human dignity, to which our civilization has in many ways been committed, if we abstract it entirely from the context of the religious beliefs that formed it. [...] I doubt, in fact, that there is any way to derive a belief in the equal worth of every human being from the 
ordinary distinctions in merit and excellence that we all use in some spheres of life; it is grounded, rather, not in our relation to each other, but in our relation to God, from whom-to use a mathematical metaphor-we are equidistant. (Meilaender 2008, pp. 262-3)

\section{(p.13) Or Leon Kass:}

The dignity of being human [...] completes itself and stands tallest when we bow our heads and lift our hearts in recognition of powers greater than our own. The fullest dignity of the god-like animal is realized in its acknowledgement and celebration of the divine. (Kass 2008, p. 329)

A distinct basis for human dignity, probably inspired by the classical Kantian conception of dignity, is the intrinsic rationality that some people believe characterizes human nature (Lee and George 2008). In contemporary conservatives, this view does not require that the high properties that distinguish humans from other animals be actualized. The core of the view seems to be that all forms of human life share an intrinsically rational nature, which makes this view overlap with the Catholic view. In other words, 'because personhood is based on the kind of being that one is-a substantial entity whose nature is rational nature-one cannot lose one's fundamental personal dignity, as long as one exists as a human being' (Lee and George 2008, p. 410).

\subsubsection{Views on Human Dignity among Proponents of Human Enhancement}

Proponents of enhancement have two main strategies to contest dignity-based arguments against enhancement. One is to reject the concept of dignity-for instance, by claiming that it is too vague or that it adds nothing to bioethical discussion (Macklin 2003). Pinker goes further and suggests that it is a stupid concept that is relative, fungible, and even potentially harmful and deceptive (Pinker 2008).

The other strategy is to argue that enhancement may actually promote human dignity by improving those qualities and virtues that confer a special worth on human beings. Nick Bostrom defends a notion of human dignity centred on the qualities that enhanced humans might possess. 'Dignity as quality', as he calls it, is a 'kind of excellence', 'a virtue or an ideal, that can be cultivated, fostered, respected, admired, promoted, etc.' (Bostrom 2008, p. 175).

\subsection{Restrictive (Non-conservative) Positions on Human Enhancement} So far we have focused on opposition to enhancement from what we have called the moral conservative camp. However, opposition may also stem from concerns about social equality or the negative consequences of enhancement. 
1.7.1 Egalitarian Concerns

A major concern about equality is that human enhancement technologies might only be affordable to the world's wealthy, or in any case to some small privileged group, thus exacerbating the already marked inequalities between rich and poor (Mehlman and Botkin 1998; Glannon 2001; McKibben 2003; Mehlman 2003). There are also fears that enhancement carried out over several generations may create two separate species, one of which will have the power to dominate the other (Silver 1999).

(p.14) One response to this objection is that we already accept significant inequalities due to differences in opportunity, and should not single out biotechnological enhancements for special criticism on this count. We accept that the rich can afford better education for their children, for instance. Nonetheless, the worry remains that enhancement may significantly worsen existing inequalities in a more radical way. As an instance of the general worry that great inequalities in society tend to undermine its stability and threaten democracy, it has also been argued that a society with significant inequalities due to genetic differences in particular would have the same socially undesirable effects (Mehlman 2003).

A second, more powerful, response from enhancement advocates is that enhancement, far from being opposed to equality, can be used to make up for the unfairness of the 'genetic lottery' (thus embracing a form of luck egalitarianism) by bringing the least fortunate up to a decent minimum of capacities and well-being. In other words, a strategy available to enhancement advocates is that of replacing a strict egalitarian with a sufficientarian notion of justice, and to argue that enhancement is required by this sufficientarian notion (Savulescu 2006). Thus we might have a policy whereby enhancements are subsidized for those who cannot afford them, so that everybody could have access to them, which would level the playing field (Mehlman 2009; Buchanan 2011).

\subsubsection{Utilitarian Concerns}

Utilitarian opposition to enhancement should also be considered. In particular, enhancement interventions might drain resources away from more useful medical research aimed at serious diseases that threaten the well-being of the global majority (Selgelid 2014). This problem already exists: only 10 per cent of medical research is used to address 90 per cent of the global burden of disease (the so-called diseases of the poor). However, this is no licence to make things even worse. As Michael Selgelid puts it, '[i]f it is safe to assume that treatment and prevention of serious disease would improve human well being to a greater extent than interventions aimed at things like greater than average height, then utility would be adversely affected in the process' (Selgelid 2014, p. 11). 
One response to such utilitarian concerns about enhancement is to say that procreative liberty trumps utilitarian considerations because individual rights generally take priority over duties towards society. A second response is that there are other utilitarian considerations in favour of enhancement that should also be taken into account-namely, the cost to society (rather than to the individual) of failing to enhance individuals (Levy 2013).

\subsubsection{Balancing Principles}

Since human enhancement raises ethical concerns about individual liberty, equality, and utility, and since such considerations are often at odds with each other, Selgelid has argued for a shift in the enhancement debate. He proposes investigating principled (p.15) ways of balancing or trading off the different concerns. Such a 'moderate pluralist' theory would determine, for instance, 'how great the equality and/or utility costs of enhancement would need to be in order for liberty infringement to be justified' (Selgelid 2014, p. 12).

\subsubsection{Autonomy and Moral Equality}

Jürgen Habermas opposes certain sorts of enhancement because of concerns about the autonomy and moral equality of future generations. The practice of morality, he contends, is based on idealizing presuppositions that each person is responsible for giving ethical shape to their life, and that each enjoys equal treatment with complete reciprocity of rights and duties (Habermas 2003, p. 92). Social influences shape us and, in that sense, mitigate our responsibility. Viewing ourselves as autonomous and responsible requires reference to a point beyond social influences. That reference point is the moment of birth, which demarcates the person's 'natural fate' from their 'socialized fate' (Habermas 2003, pp. 59-60). Yet if even this 'natural fate' is influenced by humans, we should enquire whether this changes our understanding of autonomy and responsibility.

Viewing ourselves as equals in the shared practices of moral community, Habermas claims, is incompatible with sorts of dependence which are one-way rather than reciprocal. Having one's genome 'programmed', as he puts it, places the younger generation at the receiving end of such a one-way relation. This is fine if the younger generation can be assumed to consent to the programming, something that Habermas thinks is true of therapeutic interventions (Habermas 2003 , p. 43). He contrasts genetic programming to the socializing influence of parents in child-rearing. Leaning on his wider philosophical theory, Habermas says that in the latter case, the child is involved in a reciprocal communicative process in which they can respond to the parents, which Habermas suggests does not happen in the case of the genetic enhancement of offspring. Granted, there are some permissible cases of enhancement, he thinks, such as aiming for a stronger immune system or a longer lifespan. These are highly general goals, and they can be assumed to have the consent of the future child despite the fact that the child is at the receiving end of a one-way and non-reciprocal act 
(Habermas 2003, pp. 51-2). For more specific enhancements, consent cannot be assumed. Consider the more general contrast with the transfer of culture down the generations. Whereas a future generation can question and selectively accept or reject elements of received culture, Habermas suggests that it is not in a position to reject the cumulative effect on the gene pool of generations of decisions guided by the forces of profit and individual preference (Habermas 2003, p. 72).

\subsubsection{Unintended Bad Consequences and Futility}

Some moral conservatives oppose enhancements without appealing to values peculiar to the conservative tradition. Alongside interpretations of concepts such as sanctity, dignity, and human nature, conservatives may also argue against enhancement on the grounds of overlooked bad consequences.

(p.16) Consider first the so-called 'perversity thesis', whereby certain actions or policies have unintended consequences that produce the opposite of what they were meant to promote (Hirschman 1991). An example of this is the view that there is a 'precisely balanced' human nature such that any human attempt to alter it is likely to end in disaster (President's Council on Bioethics 2002, p. 287). The perversity thesis in this sense can take two different forms: one factual and the other value oriented. Francis Fukuyama argues that, because the interactions between single genes and phenotypic traits is very complex, with any gene coding for multiple proteins, altering any single gene or genetic sequence to obtain a desirable trait might have bad unintended consequences for the expression of other desirable traits (Fukuyama 2002, pp. 74-5, 92-3). Whereas this concern is based on factual claims answerable to evidence, unintended bad consequences can also be presented in more abstract terms familiar to the conservative tradition. According to Leon Kass, for instance, with biotechnologies '[w] may get more easily what we asked for only to realize it is vastly less than what we really wanted. Worse, we may get exactly what we ask for and fail to recognize what it cost us in coin of our humanity' (Kass 2008, p. 303).

One way to address the perversity thesis is to note that it seems to involve a misconception of evolution. Consider, for instance, the idea that 'the human body and mind, highly complex and delicately balanced as the result of eons of gradual and exacting evolution, are almost certainly at risk from any illconsidered attempt at "improvement" ' (President's Council on Bioethics 2002, p. 287). Powell and Buchanan argue that the force of this point rests on a misunderstanding of how evolution works (Buchanan 2011; Powell and Buchanan 2011). Evolution is not, as the quote implies, a 'Master Engineer' that makes its creation (nature) 'a stable, completed masterpiece that can only be ruined by any human attempt to improve it' (Buchanan 2011, p. 156). Rather 'the fact that natural selection has operated on a trait does not ensure that the trait is optimal' (Buchanan 2011, p. 156). So there is room for beneficial and 
ameliorating human intervention, unless opponents of enhancement can show that the current traits or dispositions are optimal (Bostrom and Ord 2006; Kahane and Savulescu 2013).

Apart from the perversity thesis, Hirschman identifies two other common argumentative strategies typical of 'the rhetoric of reaction' (Hirschman 1991). These are the 'futility thesis' and the 'jeopardy thesis', and they are often used to argue against human enhancement.

The futility thesis targets enhancement that seeks to change human nature, rather than individual human beings. Francis Fukuyama notes that it would be extremely difficult, if not impossible, to alter human nature through genetic intervention. The human gene pool is so large that such changes would have to occur to a very large proportion of individuals and on a wide range of genes, something deemed very unlikely to happen. As he explains, 'a handful of rich people genetically modifying their children for greater height or intelligence would have no effect on species-typical height or IQ.' (Fukuyama 2002, p. 79). While this claim seems to contradict what Fukuyama himself has said about the possible unintended bad consequences of altering gene sequences, it certainly is one of the argumentative strategies available to the opponents of (p.17) human enhancement who are not committed to the 'perversity thesis'. By appealing to the futility of seeking to change human nature in this way, it might be argued that enhancement for this end is a poor use of resources better spent elsewhere.

The jeopardy thesis involves a slippery slope argument. Leon Kass argues that permitting therapeutic cloning (i.e. the creation of embryos via nuclear transfer from somatic cells in order to obtain embryonic stem cells with the same DNA as the somatic cells) would open the path to reproductive cloning (Kass 1997). He writes:

Only a few years ago, slippery slope arguments were used to oppose artificial insemination and in vitro fertilization using unrelated sperm donors. Principles used to justify these practices, it was said, will be used to justify more artificial and more eugenic practices, including cloning. Not so, the defenders retorted, since we can make the necessary distinctions. And now, without even a gesture at making the necessary distinctions, the continuity of the practice is held by itself to be justificatory. (Kass 1997, p. 24)

\subsubsection{The Old Eugenics and the New}

A common criticism, if not an argument per se, from opponents of human enhancement invokes comparisons with state-led eugenics programmes in the first half of the twentieth century. This has prompted distinctions between the 
old and the new eugenics, or between old eugenics and 'liberal eugenics' (Agar 2004).

The term 'eugenic' refers to practices aimed at promoting desirable traits in a given population (e.g. by encouraging the 'best' individuals to reproduce), or at eradicating undesirable traits (e.g. by reducing the reproduction of 'defective' individuals). When Francis Galton first coined the term 'eugenics' in 1883 (Kevles 1985, p. ix), it did not have bad connotations. It acquired negative connotations in the twentieth century due to coercive policies adopted in the US and in Scandinavian countries at the beginning of that century (including marriage restrictions of the 'unfit' and their forced sterilization), and in Germany during the Nazi era (including the killing of 'defective' children, institutionalized deficients, homosexuals, Jews, and other groups). Arguments in favour of human enhancement are often presented by moral conservatives as dangerously close to the ideas that led to Nazi eugenic programmes and other, comparable, horrors.

Proponents of enhancement distinguish it from the 'old eugenics' programmes enforced in the first half of the twentieth century. The old eugenics involved state-directed programmes based on scientifically or morally flawed premises (e.g. the alleged superiority of particular races or populations over others) and conducted by ethically unacceptable means. Contemporary proponents of human enhancement defend a 'liberal eugenics' in which people would be left free to decide whether and how to enhance themselves or their offspring (Savulescu 2001, p. 425). Some opponents of enhancement are swayed by these arguments (Fukuyama 2002, pp. 85-8) but most are not (Sandel 2004, pp. 119-20; O’Mathúna 2006; Kass 2008, p. 301; Pellegrino 2008, p. 515).

(p.18) Robert Sparrow, in particular, argues that despite the good intentions of proponents, the outcomes of the new eugenics might turn out uncomfortably similar to those of the old one. Stressing the incompatibility of strong consequentialism with liberalism, he suggests that a consequentialist argument for human enhancement cannot but entail the endorsement of a unique model of human being that has the greatest chances to have a good life in a given environment. In Sparrow's words, 'in any given environment at least, there is a "best" genome, which parents are obligated to provide for their children' (Sparrow 2011, p. 36). In Western countries, for instance, it might be a white, blond, blue-eyed male (Sparrow 2011, p. 35). If a consequentialist argument for human enhancement is to be taken seriously, Sparrow thinks that proponents of liberal eugenics should also commit to allowing state imposition of this model on the population.

\subsection{The Affective Revolution in Moral Psychology and the Conservative/ Liberal Divide}


1.8.1 Relevant Evidence from Moral Psychology and Neuroscience

Recent empirical evidence from the fields of moral psychology and neuroscience provides some reason to think that the neural and psychological correlates of conservatives' approach to certain moral issues may differ from those correlates in liberals approaching the same issues. Note that we have thus far avoided speaking of permissive views about human enhancement as specifically liberal. We wanted to avoid the impression that the liberal tradition entails a permissive stance, or that a permissive stance is only compatible with a liberal philosophy. The moral psychology literature discussed in this section, however, commonly uses the conservative/liberal categories, and we adopt these terms to reflect the literature. Nonetheless, the reader should retain in the back of their mind questions about the aptness of thinking of permissive positions on enhancement in these terms.

As we have seen above, Michael Sandel (2004) ascribes to liberals a narrow focus on three ethical concerns: a) for autonomy, b) for fairness, and c) for individual rights.

Interestingly, these three ethical concerns overlap with the three 'modules' that, according to Jonathan Haidt (2012), generally characterize the psychology of liberals. He defines modules as adaptive mechanisms that generate intuitive or emotional reactions to stimuli. As he puts it,

Modules are like little switches in the brains of all animals. They are switched on by patterns that were important for survival in a particular ecological niche, and when they detect that pattern, they send out a signal that (eventually) changes the animal's behavior in a way that is usually adaptive. (Haidt 2012, p. 123)

In humans, such signals generated by modules in our brain are our moral intuitions and emotions. Haidt argues that in making moral judgements, liberals rely on modules (p.19) sensitive to issues about liberty (vs. oppression), fairness (vs. cheating), and care (vs. harm), and therefore their moral judgements are influenced by such emotions as reactance (for violations of liberty), anger (for violations of fairness), and compassion (for violations of care). These three do not exhaust the range of moral modules and emotions, however. Expression of the full range is more consistently observed in conservatives (Graham, Haidt, and Nosek 2009; Haidt 2012). The modules that activate our sensitivity towards issues concerning loyalty/betrayal (e.g. breaking promises), authority/subversion (e.g. disobedience to moral or political authorities), and sanctity/degradation (e.g. violation of the natural order or of purity) play a more prominent role in the formation of moral and political judgements of conservatives. 
According to Haidt and many of his colleagues (e.g. Haidt and Joseph 2007; Greene 2008), moral judgements are often the product of intuitions or emotions. Reasoning is usually a post hoc exercise when justifying one's views to others. Many recent studies in moral psychology (Hauser et al. 2007), as well as fMRI (functional magnetic resonance imaging) investigations (Greene et al. 2001), seem to support the emotivist/intuitionist account of the formation of moral judgements. For instance, evidence suggests that some moral principles (e.g. that of double effect) that, if valid, might be used to justify one's moral judgements are not usually available to explicit moral reasoning even after a judgement has been made that seems to accord with use of the principles; some other moral principles apparently become available only in the form of post hoc rationalization for a certain judgement (e.g. the direct vs. indirect harm principle) (Cushman, Young, and Hauser 2003). These findings seem to indicate that the process by which we form a moral judgement is independent from reasoning about principles and values, and instead depends on intuitions for which the subject eventually looks for a rational justification.

Other empirical evidence has been interpreted as suggesting that feelings of disgust heavily affect, if not determine, people's moral judgements (Wheatley and Haidt 2005). For instance, people tend to make harsher judgements when in presence of foul air (Haidt 2012, pp. 70-1); and subjects who wash their hands before the experiment become more moralistic about issues related to purity. Zhong and Liljenquist (2006) call this the 'Macbeth effect'.

If this interpretation of the psychological evidence is correct, it might provide some grounds for understanding moral conservatives' positions in the enhancement debate, as presented in the sections above. For instance, the emphasis on the value of human nature and on human dignity might be explained, at least in part, by the prominent role played by the sanctity/ degradation module in conservatives' formation of moral judgements. The prominent role of disgust in moral evaluation could tell us something about the role of the feeling of repugnance to which some conservatives appeal, particularly in light of studies suggesting that conservatives have greater disgust sensitivity than liberals (Rozin et al. 1999; Inbar, Pizarro, and Bloom 2009).

\section{(p.20) 1.8.2 Possible Objections}

There are different ways to criticize these findings on the role of intuitions and emotions in the formation of moral judgements, as well as their alleged explanatory role for conservative stances. One is to question their relevance for moral psychology. Another is to question the conclusiveness of the empirical evidence. A third is, more specifically, to question the claim that they actually explain the conservative stances. 
As for the first type of criticism, in discussing the results of Haidt's empirical research, Jeanette Kennett and Cordelia Fine (2009) have questioned their relevance for the issue of what explains our moral judgements as opposed to other kinds of judgements. They note that the way we conceive of morality implies that a moral judgement, as opposed to other kinds of judgement, is such only if we have first reasoned about our intuitions and incorporated them into principles for which we can be held accountable. The conception of morality that Kennett and Fine propose is consistent with the idea that if exercising control over immediate reactions is not possible, then 'our moral concepts will lack application' (Kennett and Fine 2009, p. 85).

Josh May (2014) has questioned the results and methodology of many of the experiments that seem to show that disgust influences moral judgements. In particular, he suggests that such experiments show that disgust makes moral judgements harsher but not that it alters the polarity of judgements. In other words, the evidence currently available does not show that disgust determines people's beliefs about the permissibility or impermissibility of an action but only that it affects the perceived degree of goodness or badness, rightness or wrongness. It may be that disgust is a consequence, rather than a cause, of moral judgements (Giubilini 2016). This type of criticism is consistent with the more general idea, put forward, for instance, by Cordelia Fine (2006), that conscious reasoning and reflection might play a much more relevant role in the formation of our moral judgements than Haidt and colleagues grant (see also Payne 2005). Some work in moral psychology and neuroscience seems to point in this direction. For example, there are suggestions from fMRI studies that liberals display more brain activity in the anterior cingulate cortex-the area of the brain activated when a certain situation requires responses that diverge from one's habitual response tendency (Amodio, Jost, and Yee 2007). These data suggest that liberals have more neurocognitive sensitivity for altering habitual response patterns, so that liberal moral stances might be the result of the overcoming of immediate reactions.

The third criticism - that is, that such results from moral psychology and neuroscience cannot and should not be used to explain conservative stanceshas more to do with how conservatives might want to defend themselves from an implication that seems to lurk behind these empirical studies. The implication is that conservatives are simply less rational than liberals. Thus, for instance, the New Atlantis, the voice of the new American conservative wave (its editors include Yuval Levin, Roger Scruton, and Eric Cohen), ${ }^{3}$ does not hesitate to denounce as 'stupid' (New Atlantis 2003, p. 104) an (p.21) authoritative study, published in the Psychological Bulletin of the American Psychological Association, which provides evidence for the claim that the resistance to change of conservatives is mainly due to their attempt to manage uncertainty and threat, and that conservatives are in general less tolerant of ambiguity, more 
dogmatic, less open to experience, and less tolerant of uncertainty (Jost et al. 2003). ${ }^{4}$

References

Bibliography references:

Agar, Nicholas (2004). Liberal Eugenics: In Defence of Human Enhancement. Oxford: Blackwell.

Agar, Nicholas (2013). Truly Human Enhancement: A Philosophical Defense of Limits. Cambridge, MA: MIT Press.

Amodio, D. M., Jost, J. T., and Yee, C. M. (2007). 'Neurocognitive Correlates of Liberalism and Conservatism'. Nature Neuroscience 10(10): 1246-7.

Annas, G. J., Andrews, L. B., and Isasi, R. M. (2002). 'Protecting the Endangered Human: Toward an International Treaty Prohibiting Cloning and Inheritable Alterations', American Journal of Law and Medicine 28: 151-78.

Bostrom, Nick (2008). 'Dignity and Enhancement', in the President's Council on Bioethics (ed.), Human Dignity and Bioethics. Washington DC: US Government Printing Office, pp. 173-206.

Bostrom, Nick and Ord, Toby (2006). 'The Reversal Test: Eliminating Status Quo Bias in Applied Ethics', Ethics 116(4): 656-79.

Bostrom, Nick and Roache, Rebecca (2008). 'Ethical Issues in Human Enhancement', in Jesper Ryberg, Thomas Petersen, and Clark Wolf(eds), New Waves in Applied Ethics. Basingstoke: Palgrave Macmillan, pp. 120-52.

Briggle, Adam (2010). A Rich Bioethics. Notre Dame, IN: University of Notre Dame Press.

Buchanan, Allen (2008). 'Human Nature and Enhancement', Bioethics 23(3): 141-50.

Buchanan, Allen (2011). Beyond Humanity? New York: Oxford University Press.

Caplan, Arthur (2009). 'Good, Better, or Best?', in J. Savulescu and N. Bostrom (eds), Human Enhancement. Oxford: Oxford University Press, pp. 199-210.

Cohen, Eric (2006). 'Conservative Bioethics and the Search for Wisdom', Hastings Center Report 36(1): 44-56.

Cushman, F., Young, L., and Hauser, M. (2003). 'The Role of Conscious

Reasoning and Intuitions in Moral Judgment', Psychological Science 17(12): 1082-9. 
Douglas, Tom (2013). 'Human Enhancement and Supra-personal Moral Status', Philosophical Studies 162(3): 473-97.

Fine, Cordelia (2006). 'Is the Emotional Dog Wagging its Rational Tail, or Chasing It?’ Philosophical Explorations 9(1): 83-98.

Fukuyama, Francis (2002). Our Posthuman Future. Consequences of the Biotechnology Revolution. New York: Farrar, Straus and Giroux.

Giubilini, A. (2015). 'Don't Mind the Gap: Intuitions, Emotions, and Reasons in the Enhancement Debate', Hastings Center Report, 45(5): 39-47.

(p.22) Giubilini, A. (2016). 'What in the World is Moral Disgust?', Australasian Journal of Philosophy, 94(2): 227-42.

Giubilini, A. and Sanyal, S. (2015). 'The Ethics of Human Enhancement', Philosophy Compass 10(4): 233-43.

Glannon, Walter (2001). Genes and Future People. Cambridge, MA: Westview Press.

Graham, J., Haidt, J., and Nosek, B. A. (2009). 'Liberals and Conservatives Rely on Different Sets of Moral Foundations', Journal of Personality and Social Psychology, 96(5): 1029-46.

Greene, J. D., Sommerville, R. B., Nystrom, L. E., Darley, J. M., and Cohen, J. D. (2001). 'An fMRI Investigation of Emotional Engagement in Moral Judgment', Science 293: 2105-8.

Greene, Joshua (2008). 'The Secret Joke of Kant's Soul', in W. Sinnott-Armstrong (ed.), The Neuroscience of Morality: Emotions, Brain Disorders, and Development. Cambridge, MA; London: MIT Press, pp. 35-79.

Habermas, Jürgen (2003). The Future of Human Nature. Cambridge: Polity Press.

Haidt, J. and Joseph, C. (2007). 'The Moral Mind: How Five Sets of Innate Intuitions Guide the Development of Many Culture-Specific Virtues, and Perhaps even Modules', in P. Carruthers, S. Laurence, and S. Stich (eds), The Innate Mind: Foundations and the Future, Vol. 3. New York: Oxford University Press: pp. 367-92.

Haidt, Jonathan (2012). The Righteous Mind. New York: Pantheon.

Harris, John (2009). 'Enhancements are a Moral Obligation', in J. Savulescu and N. Bostrom (eds), Human Enhancement. Oxford: Oxford University Press, pp. 131-54. 
Harris, John (2011). 'Moral Enhancement and Freedom', Bioethics, 25(2): 10211.

Hauser, M., Cushman, F., Young, L., Kang-Xin Jin, R., and Mikhail, J. (2007). 'A Dissociation between Moral Judgment and Justifications', Mind and Language 22(1): 1-21.

Hirschman, Albert (1991). The Rhetoric of Reaction. Cambridge, MA: Belknap Press-Harvard University.

Inbar, Y., Pizarro, D. A., and Bloom, P. (2009). 'Conservatives are more Easily Disgusted than Liberals', Cognition and Emotions 23(4): 714-25.

Juengst, E. and Moseley, D. (2015). 'Human Enhancement', in Edward N. Zalta (ed.), Stanford Encyclopedia of Philosophy, at <http://plato.stanford.edu/ archives/sum2015/entries/enhancement>, accessed 16 June 2015.

Juengst, Eric (2009). 'What's Taxonomy Got to Do with It? "Species Integrity”, Human Rights, and Science Policy', in J. Savulescu and N. Bostrom (eds), Human Enhancement. Oxford: Oxford University Press, pp. 43-58.

Jost, T., Glaser, J., Kruglanski, A. W., and Sulloway, F. J. (2003). 'Political Conservatism as Motivated Social Cognition', Psychological Bulletin 129(3): 33975.

Kahane, Guy (2011). 'Mastery Without Mystery: Why there is No Promethean Sin in Enhancement', Journal of Applied Philosophy 28(4): 355-68.

Kahane, Guy and Savulescu, J. (2013). 'Normal Human Variation: Refocusing the Enhancement Debate', Bioethics, online first, doi:10.1111/bioe.12045.

Kamm, Francis (2009). 'What Is and Is Not Wrong with Enhancement?', in Savulescu and Bostrom (eds), Human Enhancement. Oxford: Oxford University Press, pp. 91-130.

Kass, Leon (1985). Toward a More Natural Science: Biology and Human Affairs. New York: Free Press.

Kass, Leon (1997). 'The Wisdom of Repugnance: Why We should Ban the Cloning of Humans', The New Republic 2 June: 17-26.

(p.23) Kass, Leon (2008). 'Defending Human Dignity', in President's Council on Bioethics (ed.), Human Dignity and Bioethics. Washington DC: US Government Printing Office, pp. 297-332.

Kennett, J. and Fine, C. (2009). 'Will the Real Moral Judgment Please Stand Up? The Implications of Social Intuitionist Model for Meta-ethics and Moral Psychology', Ethical Theory and Moral Practice 12(1): 77-96. 
Kekes, John (1998). A Case for Conservatism. Ithaca, NY: Cornell University Press.

Kevles, D. J. (1985). In the Name of Eugenics. Los Angeles: University of California Press.

Kirk, Russell (1994). The Conservative Mind. 7th rev. edn. Washington DC: Regnery Publishing.

Krauthammer, Charles (2002). 'Why Pro-Lifers are Missing the Point', in Kristol, Willam and Cohen, Eric (eds), The Future is Now: America Confronts the New Genetics. Lanham MD: Rowman and Littlefield, pp. 201-3.

Lee, P. and George, R. (2008). 'The Nature and Basis of Human Dignity', in the President's Council on Bioethics (ed.), Human Dignity and Bioethics. Washington DC: US Government Printing Office, pp. 409-33.

Levin, Yuval (2003). 'The Paradox of Conservative Bioethics', New Atlantis Spring: 53-65.

Levy, Neil (2013). "There May Be Costs to Failing to Enhance, as Well as to Enhancing', American Journal of Bioethics 13(7): 38-9.

Lewens, Tim (2012). 'Human Nature: The Very Idea', Philosophy and Technology 25(4): 459-74.

McKibben, Bill (2003). Enough: Staying Human in an Engineered Age. New York: Henry Holt Company.

Macklin, Ruth (2003). 'Dignity is a Useless Concept', British Medical Journal 327: 1419.

Macklin, Ruth (2006). 'The New Conservatives in Bioethics: Who Are They and What Do They Seek?', Hastings Center Report 36(1): 34-43.

May, Josh (2014). 'Does Disgust Influence Moral Judgment?', Australasian Journal of Philosophy 92(1): 125-41.

Mehlman, M. J. (2003). Wondergenes: Genetic Enhancement and the Future of Society. Bloomington, IN: Indiana University Press.

Mehlman, M. J. (2009). The Price of Perfection: Individualism and Society in the Era of Biomedical Enhancement. Baltimore: Johns Hopkins University Press.

Mehlman, M. J. and Botkin, J. (1998). Access to the Genome: The Challenge to Equality. Washington DC: Georgetown University Press. 
Meilaender, Gilbert (2008). 'Human Dignity: Exploring and Explicating the Council's Vision', in the President's Council on Bioethics (ed.), Human Dignity and Bioethics. Washington DC: US Government Printing Office, pp. 253-77.

Moreno, Jonathan (2011). The Body Politic: The Battle over Science in America. New York: Bellevue Literary Press.

New Atlantis (2003). 'Out of the Right Mind', New Atlantis 3(Fall): 103-5.

O’Mathúna, Donal (2006). 'Human Dignity in the Nazi Era: Implications for Contemporary Bioethics', BMC Medical Ethics 7: 2.

Payne, B. K. (2005). 'Conceptualizing Control in Social Cognition: How Executive Functioning Modulates the Expression of Automatic Stereotyping', Journal of Personality and Social Psychology 89(4): 488-503.

Pellegrino, Edmund (2004). Biotechnology, Human Enhancement, and the Ends of Medicine. The Centre for Bioethics and Human Dignity, 30 November. <http:// cbhd.org/content/biotechnology-human-enhancement-and-ends-medicine $>$.

(p.24) Pellegrino, Edmund (2008). 'The Lived Experience of Human Dignity', in the President's Council on Bioethics (ed.), Human Dignity and Bioethics. Washington DC: US Government Printing Office, pp. 513-39.

Peters, Ted (2002). Playing God? Genetic Determinism and Human Freedom. New York: Routledge.

Pinker, Steven (2008). 'The Stupidity of Dignity', The New Republic 8 May 2008. <http://www.newrepublic.com/article/the-stupidity-dignity>, accessed 11 November 2015.

Powell, R. and Buchanan, A. (2011). ‘Breaking Evolution's Chains: The Promise of Enhancement by Design', in Savulescu, Julian, ter Meulen, Ruud, and Kahane, Guy (eds). Enhancing Human Capacities. Oxford: Wiley-Blackwell, pp. 49-67.

President's Council on Bioethics (ed.) (2002). Human Cloning and Human Dignity: An Ethical Inquiry. Washington DC: US Government Printing Office.

President's Council on Bioethics (ed.) (2003). Beyond Therapy: Biotechnology and the Pursuit of Happiness. Washington DC: US Government Printing Office.

President's Council on Bioethics (ed.) (2008). Human Dignity and Bioethics. Washington DC: US Government Printing Office.

Roache, R. and Clarke, S. (2009). 'Bioconservatism, Bioliberalism, and the Wisdom of Repugnance', Monash Bioethics Review 28(1): 1-21. 
Rozin, P., Lowery, L., Imada, S., and Haidt, J. (1999). 'The CAD Triad Hypothesis: A Mapping between Three Moral Emotions (Contempt, Anger, Disgust) and Three Moral Codes (Community, Autonomy, Divinity)', Journal of Personality and Social Psychology 76(4): 574-86.

Sandel, M. (2004). 'The Case against Perfection', The Atlantic 293(3): 51-62.

Sandel, M. (2007). The Case Against Perfection. Cambridge, MA: Belknap Press.

Savulescu, J. (2001). 'Procreative Beneficence: Why We Should Select the Best Children', Bioethics 15(5/6): 413-26.

Savulescu, J. (2006). 'Justice, Fairness, and Enhancement', Annals of the New York Academy of Sciences, 1093: 321-38.

Savulescu, J. (2007). 'Genetic Interventions and the Ethics of Enhancement of Human Beings', In Bonnie Steinbock (ed.), The Oxford Handbook of Bioethics. New York: Oxford University Press, pp. 516-35.

Scruton, Roger (2001). The Meaning of Conservatism, 3rd edn. Basingstoke: Palgrave.

Selgelid, Michael (2014). 'Moderate Eugenics and Human Enhancement', Medicine, Health Care and Philosophy 17(1): 3-12.

Silver, L. M. (1999). Remaking Eden: Cloning, Genetic Engineering and the Future of Human Kind. London: Phoeniz.

Singer, Peter (2005). 'Ethics and Intuitions. The Journal of Ethics 9: 331-452.

Sparrow, Robert (2011). 'A Not-so-New Eugenics: Harris and Savulescu on Human Enhancement', Hastings Center Report 41(1): 32-42.

Wheatley, Thalia and Haidt, Jonathan (2005). 'Hypnotic Disgust Makes Moral Judgments More Severe', Psychological Science 16(10): 780-4.

Zhong, Chen-Bo and Liljenquist, Katie (2006). 'Washing Away Your Sins: Threatened Morality and Physical Cleansing', Science 313(5792): 1451-2.

Notes:

$\left({ }^{1}\right)$ According to Ruth Macklin, the liberal/conservative dichotomy in bioethics would imply that we should consider as conservative some feminists who oppose assisted reproductive technologies (Macklin 2006, pp. 34-5). The category 'conservative' also does not overlap with the category of 'bioconservative' (which only refers to the bioethical domain). For instance, Jonathan Moreno talks of 'bioconservative' to refer to anti-enhancement positions, whether they are from the political right or political left. On the right he sees bioconservatism as the expression of a concern for the erosion of 
traditional values and dignity, while on the left he sees it as resulting from worries about social inequality and ecological problems (Moreno 2011, p. 121). Arthur Caplan tries to avoid political connotation and talks of meliorist and antimeliorist positions, rather than liberal and conservative positions (Caplan 2009).

$\left({ }^{2}\right)$ However, as C. A. J. Coady argues in Chapter 2, it might be wrong to think of reason and emotions as forming a dichotomy. Because some emotions do have cognitive content, they are essential to practical rationality.

$\left(^{3}\right)$ The editors are listed at <http://www.thenewatlantis.com/about/masthead $>$.

( $\left.{ }^{4}\right)$ We would like to thank Steve Clarke, Neil Levy, Jonathan Pugh, and Rebecca Roache for useful comments and suggestions on previous drafts of this chapter.

\section{Access brought to you by:}

